\title{
Hospital morbidity and colorectal cancer mortality: implications for public health in Brazil
}

\author{
Ramona Garcia Souza DOMINGUEZ1 and Ana Luiza BIERRENBACH²
}

Received: 20 January 2020 Accepted: 25 March 2020

\begin{abstract}
Background - Colorectal cancer is a serious public health problem and one of the most common cancer worldwide. Countries around the world have shown different trends. While incidence and mortality rates for colorectal cancer are on an upward trend in developing countries, these rates have been on a downward trend in most developed countries. Objective - To analyze the temporal trend of morbimortality by colorectal cancer in Brazil between 2002 and 2016. Methods - Descriptive, time series research. Data were extracted from the national information systems for hospitalizations and deaths of the respective years. Results - There were increasing trends in hospital morbidity and mortality from colorectal cancer in all regions of the country, with the very elderly individuals dying at a higher rate. Women $(52.1 \%)$ were more affected than men, but death rates were higher for males aged 60 years or more. Regional disparities were evident, with almost $80 \%$ of deaths occurring in the South and Southeast, with the largest annual increase in the South and the lowest in the North. Regarding hospitalization, South and Southeast presented higher annual growths. Conclusion -These data add knowledge about the profile of public hospitalizations and deaths, reaffirming that colorectal cancer contributes to an important burden of disease and mortality in Brazil. These elements have implications for the review of colorectal cancer prevention and control strategies, as well as for public health investments.
\end{abstract}

HEADINGS - Colorectal neoplasms, mortality. Morbidity. Public health. Medical oncology.

\section{INTRODUCTION}

Cancer is a serious worldwide public health problem. The Brazilian National Cancer Institute (INCA) estimated for the biennium 2018-2019, in Brazil, 17,380 new cases of colorectal cancer (CRC) in men and 18,980 in women. As a result, CRC appears as the third type of cancer with greatest incidence in the Brazilian population, occupying 2nd place among women and 3rd place among men ${ }^{(1)}$.

Countries around the world have different CRC mortality trends. The Globocan report demonstrates that the incidence and mortality rates for CRC are on an upward trend in developing countries, such as Colombia and Costa Rica, while in the developed countries these rates have remained on a downward trend for many years (USA, New Zealand, Australia and Canada). Such disparities may be associated to different lifestyle habits, as well as to the inequity of the availability of resources for early diagnosis and treatment ${ }^{(2)}$.

A study in 34 European countries and in the United States (USA), with data from the World Health Organization (WHO) in the period of 1970-2011, demonstrated a downward trend with a reduction in mortality of over $25 \%$ among men and 30\% among women in Austria, Belgium, Germany, Czech Republic, Luxembourg and Ireland, for example. In the United Kingdom, there was a 30\% drop in mortality rates for both genders (1989-2011), with an annual decrease of $2.0 \%$ and in the USA the reduction reached $39.8 \%$ for men and $38.8 \%$ for women ${ }^{(3)}$.
Due to its high morbidity and mortality, CRC brings relevant social and economic consequences to the societies. In the USA, for example, deaths by CRC of individuals between the ages of 50 and 74, occurring between 2008 and 2012, resulted in approximately US\$ 2 billion dollars in loss of productivity per year, being considered as potentially avoidable deaths ${ }^{(4)}$.

CRC, in general, affects individuals of ages 55-60 or over, in whom, approximately $80 \%$ of the cases, the disease arises in a sporadic manner. Apart from age, other risk factors are well characterized, such as individual and family clinical history, occurrence of intestinal polyps, diet, obesity, alcoholism, smoking and diabetes, with some of these being changeable and/or preventable ${ }^{(5)}$.

Access to diagnosis services and treatment, as well as to strategies for screening the disease can be considered as factors that have the potential of decreasing the incidence and, at the same time, directly reducing the $\mathrm{CRC}$ mortality rates ${ }^{(6)}$.

To broaden the discussion on health services and in order to be able to report data on hospital incidence, this research aggregates the data analysis on hospital morbidity and mortality for CRC, inexistent in the above-mentioned studies and a scant subject of literature in Brazil. This information enables assessment and guidance on the adoption of control and prevention strategies in the scope of public policies, considering regional differences and socioeconomic implications. Accordingly, the objective of this study was to analyze the temporal trend of morbidity and mortality due to CRC in Brazil, between 2002 and 2016.

Declared conflict of interest of all authors: none

Disclosure of funding: no funding received

${ }^{1}$ Universidade Federal do Recôncavo da Bahia (UFRB), Santo Antônio de Jesus, BA, Brasil. ${ }^{2}$ Instituto de Ensino e Pesquisa do Hospital Sírio Libanês (IEP-HSL), São Paulo, SP. Brasil.

Corresponding author: Ramona Garcia Souza Dominguez. E-mail: ramonagarcia@ufrb.edu.br. 


\section{METHODS}

The study used data on deaths and hospitalizations due to CRC in Brazil, in the period between 2002 and 2016. Individual data were extracted from the Information System on Mortality (Sistema de Informações sobre Mortalidade - SIM) and aggregated data from the Hospital Information System (Sistema de Informações Hospitalares $-\mathrm{SIH}$ ). Both systems are public and data can be downloaded from the Internet.

Only the underlying causes of death registered in accordance with the tenth review of the International Classification of Diseases (ICD-10), with codes C18.0-C18.9 for colon and C19 to C21 for rectal cancer, rectosigmoid junction, anal channel and anus, were considered as deaths by CRC. For hospitalizations, these same codes were used to classify the field designate as the main diagnosis. Population data were originally obtained from the Brazilian Institute of Geography and Statistics (IBGE).

The crude and standardized annual rates of notification of death and hospitalization due to CRC per 100,000 persons per year were calculated for each region of the country, gender and age group. The annual increase in the rates was estimated using simple linear regression models. $P<0.05$ values were considered as statistically significant. For data management and analysis, Excel program and Stata software version 12 were used. The Ethics Committee of the Syrian Lebanese Hospital approved the study under CAAE no. 29183314.1.0000.5461.

\section{RESULTS}

In this research, a rising trend in hospital morbidity and mortality rates due to CRC was observed in Brazil between 2002 and 2016 (FIGURE 1). Hospitalization rates for CRC presented an annual increase of 1.48 per 100,000 persons per year $(P<0.001)$ and a standardized rate of 0.96 per $100,000(P<0.001)$. The CRC mortality rate presented an annual increase of 0.26 deaths per 100,000 person-years $(P<0.001)$ and a standardized rate of 0.06 per 100,000 person-years $(P<0.001)$.

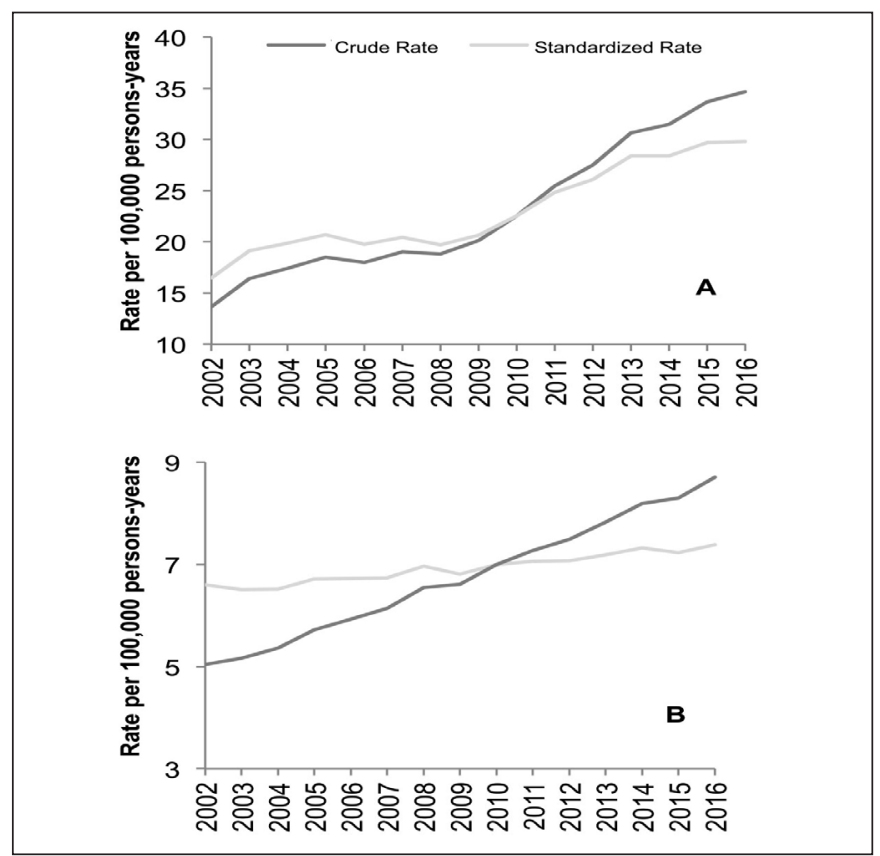

FIGURE 1. Colorectal cancer morbidity and mortality rates. Brazil from 2002 to 2016. (A) Hospitalization; (B) Deaths.

The comparison between the years 2002 and 2016 demonstrated an increase in the hospitalization and death rates by CRC, considering the total amount of cases and separately for both genders, for each age group and region. The highest hospitalization rate was found in individuals of ages 70-79 years (175.4 per 100,000) and the highest death rate occurred in the elderly age group ( $\geq 80$ years, 107.1 per 100,000$)$.

The total number of women deceased with $\mathrm{CRC}$ as the underlying cause of death was higher than that of the men, but the proportion and death rates increased with increasing age for both genders (TABLE 1).

TABLE 1. Colorectal cancer morbidity and mortality by epidemiologic aspects. Brazil from 2002 to 2016.

\begin{tabular}{|c|c|c|c|c|c|c|c|c|c|c|c|c|}
\hline \multirow{2}{*}{$\begin{array}{l}\text { Year } \\
\text { Variable }\end{array}$} & \multicolumn{6}{|c|}{2002} & \multicolumn{6}{|c|}{2016} \\
\hline & \multicolumn{3}{|c|}{ Hospitalization } & \multicolumn{3}{|c|}{ Death } & \multicolumn{3}{|c|}{ Hospitalization } & \multicolumn{3}{|c|}{ Death } \\
\hline \multicolumn{13}{|l|}{ Sex } \\
\hline Female & 11,425 & 48.1 & 12.9 & 4,683 & 53.4 & 5.3 & 34,944 & 49.6 & 33.6 & 8,868 & 50.1 & 8.5 \\
\hline \multicolumn{13}{|l|}{ Age } \\
\hline $0-49$ & 11,903 & 50.2 & 8.2 & 1,241 & 14.1 & 0.9 & 15,604 & 22.1 & 9.9 & 1,783 & 12.3 & 1.2 \\
\hline $60-69$ & 3,955 & 16.7 & 44.9 & 2,078 & 23.7 & 23.6 & 20,349 & 28.9 & 153.6 & 4,476 & 23.8 & 33.8 \\
\hline $70-79$ & 3,180 & 13.4 & 65.2 & 2,444 & 27.9 & 50.1 & 12,935 & 18.4 & 175.4 & 4,388 & 24.9 & 59.5 \\
\hline $80+$ & 1,047 & 4.4 & 51.0 & 1,596 & 18.2 & 77.7 & 4,206 & 6.0 & 116.9 & 3,853 & 21.7 & 107.1 \\
\hline \multicolumn{13}{|l|}{ Regions } \\
\hline Midwest & 1,398 & 5.9 & 11.6 & 441 & 5.0 & 3.6 & 4,560 & 6.5 & 29.4 & 1,109 & 6.3 & 7.1 \\
\hline Northeast & 3,693 & 15.6 & 7.6 & 878 & 10.0 & 1.8 & 10,370 & 14.7 & 18.4 & 2,690 & 15.2 & 4.8 \\
\hline Total & 23,732 & - & 13.6 & 8,772 & - & 5.0 & 70,475 & - & 34.7 & 17,698 & - & 8.7 \\
\hline
\end{tabular}

* Rate by 100,000 person-years. 
Regional disparities were evident. The South and Southeast regions concentrate almost $80 \%$ of hospitalizations and the highest death rates due to CRC. Hospitalization rates were lower in the North and Northeast regions. In this study, it was observed that death rates increased mainly in Northeast and Midwest regions of Brazil.

The trend analysis of the hospital morbidity and mortality rates by age groups and gender evidenced a similar pattern between men and women aged 60 and younger. However, rates were predominant for the male gender in the other age groups. In 2007, specifically among people aged 80 years and older, there was an inversion in the mortality rate with predominance of deaths among men, which was maintained until the end of the studied period (FIGURE 2).

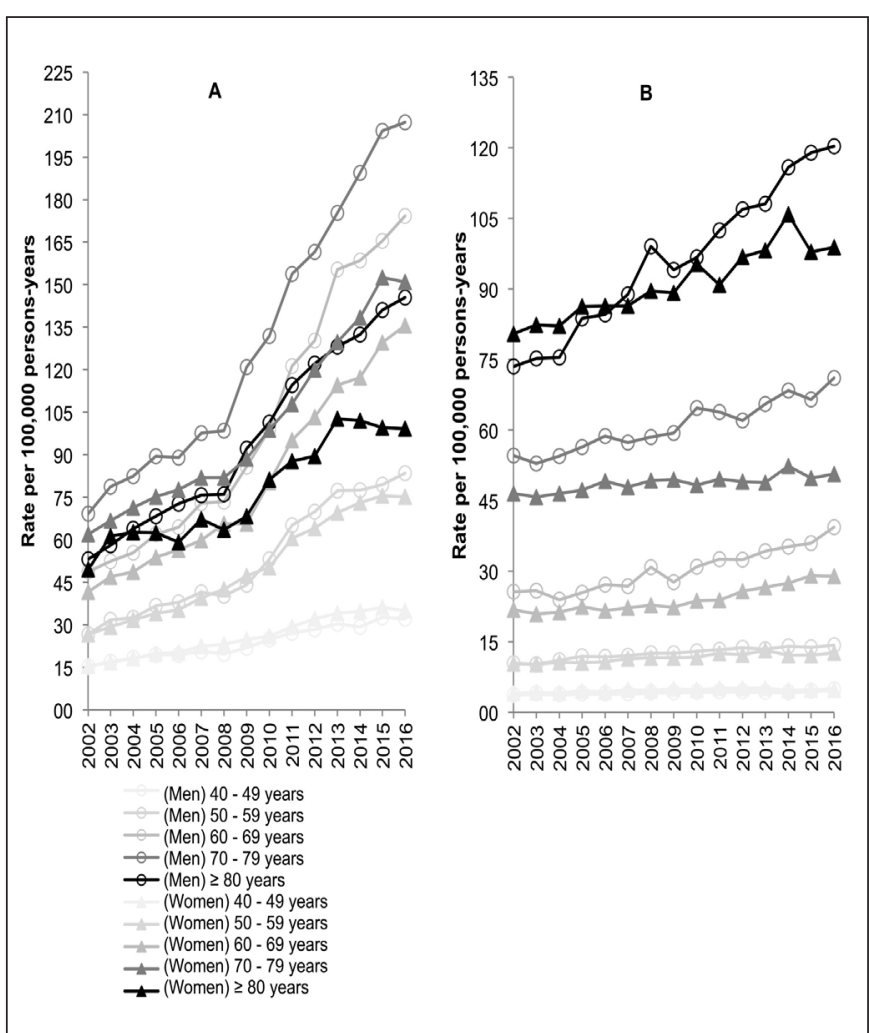

FIGURE 2. Colorectal cancer morbidity and mortality rates by age groups and sex. Brazil from 2002 to 2016. (A) Hospitalization; (B) Deaths.

Comparing data by regions, their hospitalization rates showed significant growing trends due to $\mathrm{CRC}(P<0.001)$, with exception to the Northern region. This growth was more significant in the South (3.3 per 100,000/year), representing an increase of over $170 \%$ in the comparison between 2002 and 2016, followed by the Southeast $(+1.8 / 100,000)$ and Midwest $(+1.1 / 100,000 /$ year $)$. In the Northeast, the annual increase was of 0.67 hospitalizations per $100,000 /$ year $(P<0.001)$ (FIGURE 3).

There was also a steady increase in the death rates for CRC for all regions in Brazil. The growing trends were statistically significant and greater in the South (0.33 deaths per 100,000/year) and Southeast ( 0.31 per $100,000 /$ year), overcoming the growth curve for Brazil as a whole. The third highest mortality rate for CRC was observed in Midwest with an annual increase of 0.27 deaths per $100,000 /$ year, followed by Northeast ( 0.22 deaths per $100,000 /$ year $)$ and Northern region ( 0.15 deaths per $100,000 /$ year) (FIGURE 3 ).

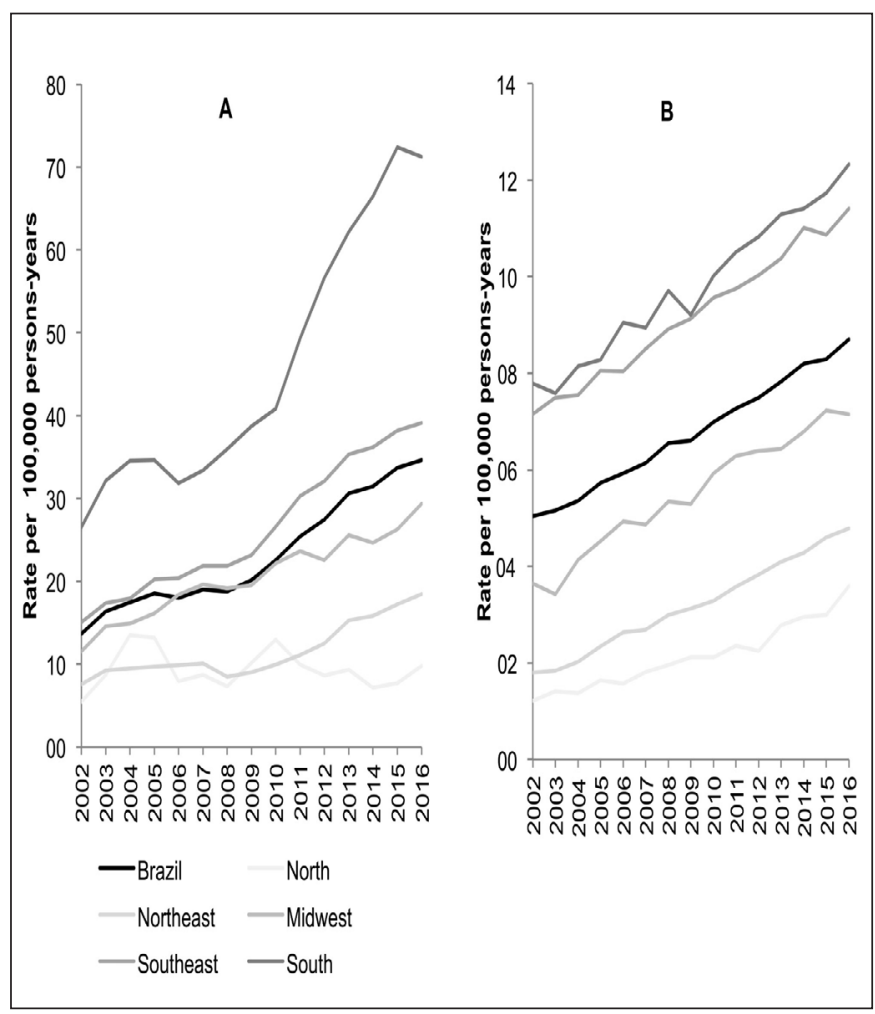

FIGURE 3. Colorectal cancer morbidity and mortality rates by regions. Brazil from 2002 to 2016. (A) Hospitalization; (B) Deaths.

\section{DISCUSSION}

In this study, a growing trend was observed in the morbidity and mortality rates for CRC in Brazil. It was possible to verify that $\mathrm{CRC}$ hospitalizes and kills more elderly patients and, despite the number of women deceased being superior to men, rates were higher for the male gender, especially in the age group of 60 years and older.

Multiple factors are involved to explain this increasing trend. Part of this increase reflects epidemiological changes, with the consequent increase in the CRC incidence, due to greater exposure to risk factors, as well as to access to treatment difficulties that contribute towards reducing the survival rate of the patients.

However, the increase in the capacity of the health system to perform the diagnosis of the disease due to better access to health, training and technology over the study period can also be considered as a factor that could be contributing to an increase in these rates. Despite greater overall access to diagnosis, it is possible that this is occurring late in the natural history of the CRC disease, impairing treatment and aggravating the prognosis of patients ${ }^{(7)}$.

Similarly, the growing trends in morbidity and mortality due to CRC should also be analyzed under the viewpoint of the changes, usually for the better, that occurred in the respective information systems throughout the studied period, as mentioned below.

Among the factors influencing high-incidence and mortality are the increasing life expectancy in the country ${ }^{(1)}$, increased exposure to risk factors and decreased exposure to known protective factors for the disease. The demographic and epidemiological transition in Brazil should also be highlighted, with the aging of the population and increased deaths due to chronic diseases ${ }^{(7)}$. 
Age is an important risk factor for diseases that have a slow evolution and where the exposure to carcinogens accumulates over time, as is CRC. Almost $80 \%$ of CRC cases can be classified as sporadic, in other words, products of an insidious evolution and consequently more frequent in the elderly ${ }^{(5)}$.

Despite this, the increasing life expectancy throughout the period studied explains only part of the raising rates. This is evidenced in the comparison of the standardized and crude rates, for both hospitalization and death. The crude rates were, as expected, more inclined than the standardized rates, which reflects that the aging population is not the only factor explaining the increasing trend.

Other risk factors commonly involved include individual and family clinical history for the disease, diets with a high content of fat and red meat, obesity, alcoholism, smoking, diabetes and inflammatory diseases of the colon ${ }^{(8)}$.

Differently from what was observed in Brazil, the CRC incidence declined in the USA which is attributed to a lower exposure to known risk factors of the disease (consumption of processed meat) and greater exposure to protection factors (use of anti-inflammatory non-hormone analgesics, hormone reposition therapy and statins), as well as the availability of diagnostic resources and early removal of intestinal polyps with or without the presence of in situ tumors ${ }^{(6)}$.

In England, it was evidenced that living in economically underprivileged areas impairs access to health and the care of patients with $\mathrm{CRC}^{(9)}$. Socioeconomic and cultural discrepancies among the regions influence not only the exposure to risk factors, which tends to cause a greater incidence of CRC among the residents of more developed regions, but also influence access of the patients to hospital services in Brazil, being unfavorable for residents of the poorer regions ${ }^{(10,11)}$.

The improvement of access to diagnosis in Brazil observed over the study period may also have affected CRC mortality for the simple fact that deaths previously incorrectly recorded as unspecific underlying causes (for example, cancer code without any specific location) or ill-defined, were correct registered as CRC in underlying cause of death.

In Brazil, there was an important decline in the number of illdefined causes of death, resulting from a well-succeeded intervention of the Ministry of Health. This proportion is considered as an important quality indicator of mortality information systems ${ }^{(12)}$.

Another indicator is the coverage of the information system. In Brazil, the death register coverage climbed from $80 \%$ in $1980-1991$ to over $95 \%$ in $2000-2010^{(13)}$. There are still losses in the municipalities that are further away from the capital cities, mainly in the elderly group. Nevertheless, the proportion of deaths with ill-defined causes decreased during the period of the study, especially in the North and Northeast regions.

The investigations of ill-defined causes of death demonstrated that, after reclassification, cancers had a lower representation, contrary to the endocrine diseases, mental disorders, nervous system, circulatory system and maternal causes ${ }^{(14)}$. These findings reveal that the representativeness of CRC among the ill-defined causes is substantially lower in relation to other diseases. In other words, improvements in the SIM cannot be separately responsible for the increase in CRC mortality, including North and Northeast regions.

As regards the $\mathrm{SIH}$, despite the fact that its use has been increasingly common in epidemiological studies, the quality of information can be questioned in relation to the selection of the codes used to describe the main and the subsidiary clinical conditions ${ }^{(15)}$. In
2008, changes were made in the table of values used by SUS (public health system) to pay for hospital services, which could interfere with trends in specific codes, but there was no marked change at that time in trends observed for CRC.

As a result of the oncological healthcare network expansion, which started as a public policy in $2005^{(16)}$, the capacity and access to CRC diagnosis presented an improvement in the period studied. In 2016, there were 510 qualified services for oncology in Brazil but, when regional distribution is analyzed, considering only qualified public hospitals for this field of expertise, it is evident that most of these services $(72 \%)$ are located in economically developed regions (South and Southeast) ${ }^{(17)}$.

However, even in the locations where this network is physically implemented, there are still difficulties in access resulting from incipient regulatory system and lack of professionals (especially for surgeons and oncologists), as well as shortage of investments in treatment, primary and secondary preventions ${ }^{(18)}$.

Early detection of CRC can lead to improvements in survival. Nevertheless, the structure of the oncological healthcare network does not yet enable a timely and equitable access to cancer diagnosis and treatment, despite the increase in the number of qualified establishments for this medical specialty. The reality of the Brazilian public health has been marked by insufficient and/or misguided investments, low incorporation of new technologies and limited access to effective treatment ${ }^{(18)}$. All of these factors contribute to advanced-stage cancer at the time of diagnosis.

Data related to new cases of CRC in the municipality of São Paulo, demonstrates that diagnosis occurs in advanced stages: $28.2 \%$ in stage III and $23.2 \%$ in stage IV of the TNM staging system, which assesses the size and extent of the main tumor (T), number of nearby lymph nodes that have cancer $(\mathrm{N})$ and presence of metastases (M); consequently, a very poor prognosis ${ }^{(5)}$.

The late detection of CRC negatively influences patient's survival, collaborating to an increase in the morbidity and mortality rates observed in this study. The fact that the rates have a rising trend necessarily generates questions on the prioritization of primary and secondary prevention services, emphasizing the importance of the correct management of the resources allocated to the oncological healthcare network.

Early detection of CRC presents the peculiarity of enabling the prevention of the disease, permitting the identification and removal of intestinal polyps that have a indolent development (leading to a reduction of occurrence), diagnosis in early stages which, when adequately treated, can raise the survival rate in five years to $90 \%$ and reduce mortality ${ }^{(19)}$.

Population-based screening for cancer encompasses a complex structure that must meet certain criteria in order to guide the policies in the countries that consider the organization of these programs: 1) an important public health problem; 2) accepted treatment for patients with recognized disease; 3) availability of facilities for diagnosis and treatment; 4) recognizable latent or early symptomatic stage; 5) suitable test or examination; 6) test should be acceptable to the population; 7) natural history of the disease must be adequately understood; 8) agreed policy on whom to treat as patients; 9) cost-effectiveness of the casefinding must be economically balanced in relation to possible expenses on medical care as a whole; 10) case-finding should be a continuing process ${ }^{(20)}$.

Population-based screening for CRC meets those criteria. The experience in CRC screening program, developed in USA, demon- 
strated a reduction in $\mathrm{CRC}$ incidence and mortality rates in men and women since the $1980 \mathrm{~s}^{(20)}$. The extension of CRC screening programs is a pertinent and cost-effective strategy, considering that the costs of its implementation, despite being high, are lower than the costs associated to treatment of advanced disease and that cases avoided as a result of early detection, gradually contribute to reduce the health service costs. In addition, the reduction in CRC incidence and mortality causes economic impacts with the potential of interfering in productivity loss.

CRC hospital morbidity and mortality trends can be analyzed to identify the impact of screening, with a view of driving efforts aimed at improving outcomes and reducing $\operatorname{costs}^{(20)}$. CRC screening does not explain the modifications founded in this time series study, mainly because presently there are no governmental programs for population-based CRC screening in Brazil. In addition, even if governmental programs were being planned, it would take a long time to be actually established due to the absence of the necessary infrastructure that requires high technological investments and personnel training.

This is not an easy task and even less so immediate, considering the territorial extension and socioeconomic differences. Therefore, it can only be implemented if it is defined as a priority and all the required resources are correctly identified for the necessary interventions. As a country, we cannot ignore that year after year the number of people, mostly elderly individuals, occupying hospital beds and dying of CRC is increasing, despite this being a preventable disease.

\section{CONCLUSION}

In the studied period, it was observed a rising trend in CRC incidence and mortality in Brazil from 2002 to 2016, with higher mortality rates founded in elderly patients.
In general, women $(52.1 \%)$ were more affected than men, but CRC mortality rates were higher for men aged 60 years and over. Regional disparities were evident, with almost $80 \%$ of the deaths occurring in the South and Southeast regions, the mortality rates presented a higher annual increase in the South region and lower values in the Northeast region.

Corroborating mortality data, a rising trend was evidenced in CRC hospital morbidity. The hospitalization rates were similar in both sexes aged $\leq 60$ years and higher for men at advanced ages. South and Southeast presented a higher annual increase in hospitalization rates due to this disease.

The use of secondary data does bring limitations to this study regarding the quality and coverage of the information on causes of death and hospitalization diagnosis. Nevertheless, data does not improve per se. It needs to be used and interpreted. The information generated herein can be used as the basis for the review of prevention and control strategies of this disease.

\section{Authors' contribution}

Dominguez RGS contributed to the conception, design, implementation of the research and acquisition of data; to the analysis of the results and to the writing of the manuscript. Participated in drafting the article, gave final approval of the version to be submitted and any revised version.

Bierrenbach AL made substantial contributions to conception and design, acquisition of data, analysis and interpretation of data. Participated in revising the article critically for important intellectual content and gave final approval of the version to be submitted and any revised version.

\section{Orcid}

Ramona Garcia Souza Dominguez: 0000-0002-3131-3953.

Ana Luiza Bierrenbach: 0000-0002-6837-0636.

Dominguez RGS, Bierrenbach AL. Morbidade hospitalar e mortalidade por câncer colorretal: implicações para a saúde pública no Brasil. Arq Gastroenterol. 2020;57(2):182-7.

RESUMO - Contexto - O câncer colorretal é um grave problema de saúde pública e um dos tipos mais comuns de câncer no mundo. Diferentes tendências têm sido observadas nos países ao redor do mundo. Enquanto as taxas de incidência e mortalidade por câncer colorretal apresentam tendência crescente em países em desenvolvimento, essas taxas têm se mantido em tendência decrescente nos países mais desenvolvidos. Objetivo - Analisar a tendência temporal de morbimortalidade por câncer colorretal no Brasil, entre 2002 e 2016. Métodos - Pesquisa descritiva de série temporal. Os dados foram extraídos dos sistemas nacionais de informação de Internações Hospitalares e Mortalidade, nos anos respectivos. Resultados - Observou-se tendência crescente da morbidade hospitalar e mortalidade por câncer colorretal em todas as regiões do país, constatando-se que morrem mais idosos em idade avançada. As mulheres (52,1\%) foram mais acometidas do que os homens, porém as taxas de óbito foram maiores para o sexo masculino a partir dos 60 anos de idade. As disparidades regionais ficaram evidentes, sendo que quase $80 \%$ das mortes ocorreram nas regiões Sul e Sudeste, com maior incremento anual na região Sul e menor na região Norte. Em relação à hospitalização, Sul e Sudeste apresentaram maior crescimento anual. Conclusão - Os dados agregam conhecimento sobre o perfil das hospitalizações públicas e mortes, reafirmando que o câncer colorretal contribui para uma importante carga de doença e mortalidade no Brasil. Esses elementos trazem implicações para a revisão das estratégias de prevenção e controle do câncer colorretal, bem como para os investimentos na saúde pública.

DESCRITORES - Neoplasias colorretais, mortalidade. Morbidade. Saúde pública. Oncologia. 


\section{REFERENCES}

1. Instituto Nacional de Câncer (INCA). Estimativa 2018. Brasília (DF); 2018. 124p [Internet]. [Accessed 2019 Nov 12]. Available from: https://portaldeboaspraticas.iff.fiocruz.br/wp-content/uploads/2019/10/estimativa-incidencia-de-cancer-no-brasil-2018.pdf

2. Bray F, Ferlay J, Soerjomataram I, Siegel RL, Torre LA, Jemal A. Global cancer statistics 2018: GLOBOCAN estimates of incidence and mortality worldwide for 36 cancers in 185 countries. CA Cancer J Clin. 2018;68:394-424.

3. Ait Ouakrim D, Pizot C, Boniol M, Malvezzi M, Boniol M, Negri E, et al. Trends in colorectal cancer mortality in Europe: retrospective analysis of the WHO mortality database. BMJ, 2015;351:h4970.

4. Weir HK, Li C, Henley SJ, Joseph D. Years of life and productivity loss from potentially avoidable colorectal cancer deaths in U.S. counties with lower educational attainment (2008-2012). Cancer Epidemiol Biomarkers Prev. 2017;26:736-42.

5. Epidemiology and Information Coordination (CEInfo). Colorectal cancer screening: a challenge to be faced. [Internet] Sao Paulo: Municipal Health Secretary, 2012. [Internet]. [Accessed 2019 June 23]. Available from: https://www.prefeitura. sp.gov.br/cidade/secretarias/upload/saude/arquivos/publicacoes/Boletim_CEInfo_Analise_06.pdf

6. Welch HG, Robertson DJ. Colorectal cancer on the decline - why screening can't explain it all. N Engl J Med. 2016; 374:1605-7.

7. Brasil. Ministério da Saúde. Secretaria de Vigilância em Saúde. Departamento de Vigilância de Doenças e Agravos não Transmissíveis e Promoção da Saúde. Saúde Brasil 2018: Uma análise da situação de saúde e das doenças e agravos crônicos: desafios e perspectivas. Brasilia (DF): Ministério da Saúde, 2019. 424p. [Internet]. [Accessed 2019 June 12]. Available from: http://bvsms.saude.gov.br/bvs/ publicacoes/saude_brasil_2018_analise_situacao_saude_doencas_agravos_cronicos_desafios_perspectivas.pdf

8. Saracci R, Wild CP. International Agency for Research on Cancer: the First 50 Years. Lyon, France: International Agency for Research on Cancer; 2015. 259p. [Internet]. [Accessed 2019 December 12]. Available from: https://publications. iarc.fr/Non-Series-Publications/The-History-Of-Iarc/International-Agency-ForResearch-On-Cancer-The-First-50-Years-1965-2015

9. Raine R, Wong W, Scholes S, Ashton C, Obichere A, Ambler G. Social variations in access to hospital care for patients with colorectal, breast, and lung cancer between 1999 and 2006: retrospective analysis of hospital episode statistics. BMJ. 2010;340:b5479-b5479.
10. Victora CG, Barreto ML, do Carmo Leal M, Monteiro CA, Schmidt MI, Paim J, et al. Health conditions and health-policy innovations in Brazil: the way forward. Lancet. 2011;377:2042-53.

11. Pagotto V, Silveira EA, Velasco WD. The profile of hospitalizations and associated factors among elderly users of the Brazilian Unified Health System (SUS). Ciência\& Saúde Coletiva, 2013;18:3061-70.

12. Mikkelsen L, Phillips DE, AbouZahr C, Setel PW, de Savigny D, Lozano R, et al. A global assessment of civil registration and vital statistics systems: Monitoring data quality and progress. Lancet. 2015;386:1395-406.

13. Lima EEC, Queiroz BL. Evolution of the deaths registry system in Brazil: associations with changes in the mortality profile, under-registration of death counts, and ill-defined causes of death. Cad Saude Publica. 2014;30:1721-30.

14. França EB, Teixeira R, Ishitani L, Duncan BB, Cortez-Escalante JJ, Morais NOL, et al. Ill-defined causes of death in Brazil: a redistribution method based on the investigation of such causes. Rev Saude Publica. 2014;48:671-81.

15. Machado JP, Martins M, Leite IC. Quality of hospital databases in Brazil: some elements. Rev Bras Epidemiol. 2016;19:567-81.

16. Ministry of Health (Brazil). Ministerial ordinance no. 2,439 of December 8th, 2005. Establishes the National Cancer Care Policy: Promotion, Prevention, Diagnosis, Treatment, Rehabilitation and Palliative Care, to be implemented in all federated units, respecting the competences of the three management spheres. Official Diary of the Federative Republic of Brazil. Brasilia (DF), December 9th, 2005; Section 1, p.80-1.

17. Brasil. Ministério da Saúde. Department of Informatics at SUS (DATASUS). In: The National Database on Health Units (CNES) [Internet]. [Accessed 2018 December 23]. Available from: http://cnes.datasus.gov.br/Mod_Hospitalar.asp?VCom.

18. Federal Court of Audit (TCU). Operational Audit Report: National Oncology Care Policy. 2011. [Internet]. [Accessed 2019 December 23]. Available from: https://portal.tcu.gov.br/lumis/portal/file/fileDownload.jsp?inline=1\&fileId=8A8182A14D6E85DD014D7327C1CB5497.

19. Brasil. Ministério da Saúde. Department of Health Care, Department of Primary Care. Screening. Brasilia (DF): Ministry of Health; 2013. 95p. [Internet]. [Accessed 2019 June 23]. Available from: http://bvsms.saude.gov.br/bvs/publicacoes/ rastreamento_caderno_atencao_primaria_n29.pdf

20. Shieh Y, Eklund M, Sawaya GF, Black WC, Kramer BS, Esserman LJ. Population-based screening for cancer: hope and hype. Nat Rev Clin Oncol. 2016;13:550-65. 